\title{
Imprints of nonlinearity in radioactive gas Radon-222 expelled out of Bakreswar hot spring, India
}

\author{
Chiranjit Maji*,1, Nimagna Hazra ${ }^{2}$, Animesh Datta $^{2}$, Hirok Chaudhuri ${ }^{1}$, \\ A. N. Sekar Iyengar ${ }^{3}$ \\ (1) Department of Physics, National Institute of Technology Durgapur, India \\ (2) Department of Electronics and Communication Engineering, National Institute of Technology Durgapur, India \\ (3) Plasma Physics Division, Saha Institute of Nuclear Physics, Homi Bhabha National Institute, Kolkata, India
}

Article history: received April 2, 2019; accepted January 15, 2020

\begin{abstract}
Nonlinear time series analysis of data related to the radioactivity profile of a hot spring area can explore the dynamics of the geothermal activities along with other different nonlinear features of the Earth system. However, not much work in this field has been done so far in India. In this paper nonlinear time series analysis of the radioactive gas Radon-222 $\left({ }^{222} \mathrm{Rn}\right)$ (time series) data recorded at Bakreswar hot spring area of West Bengal, India during the period 2005-2010 was carried out to investigate the dynamics of the radioactive gas emanation process and its relation with the Earth's tide. Power spectral density and the Hurst exponents were obtained for the above said time series signal using the nonlinear techniques of Fast Fourier Transform (FFT) and power law scaling relationship. An attempt was also made to understand the system dynamics using the surrogate and truncated data of the original time series as well. The result shows that the seasonal variations of the ${ }^{222} \mathrm{Rn}$ emission from the hot spring is highly influenced by the Earth's tidal effects, and the same has been confirmed by the power spectral density plot. The estimated Hurst exponent from log p-log f plot reflects the anti-persistent Brownian motion nature of the whole five years recorded data set.
\end{abstract}

Keywords: Nonlinear time series analysis, FFT, Hurst exponent, Power spectra, ${ }^{222} \mathrm{Rn}$, Hot spring.

\section{Introduction}

Radioactivity is present everywhere on the planet Earth, where the genesis of the natural radioactivity is linked to the disintegration of radio-nuclei ${ }^{238} \mathrm{U},{ }^{235} \mathrm{U},{ }^{232} \mathrm{Th}$, and ${ }^{40} \mathrm{~K}$ present in the Earth's crust with sufficient abundances [Chaudhuri et al., 2010; Chaudhuri et al., 2018]. Monitoring and mapping of the crustal and environmental radioactivity is a major concern of research for different scientists throughout the globe to understand the dynamics of the various terrestrial phenomena and their effects on the environment [Neri et al., 2016; Tarakçı et al., 2014; İçhedef et al., 2014; Virk, 1993; Wakita et al., 1985]. ${ }^{222} \mathrm{Rn}$ (Radon-222) is an important precursor as reported by 


\section{Chiranjit Maji et al.}

several researchers [Neri et al., 2016; Tarakçı et al., 2014; İçhedef et al., 2014; Zmazek et al., 2005]. ${ }^{222} \mathrm{Rn}$ is a colourless, odourless radioactive noble gas that is normally found in the Earth's crust and the environment everywhere with different concentrations depending on the accumulation of the radio-nuclei in the bedrock, the underlying structure of the crust and meteorological conditions of the environment [Pereira, 1980]. Radon has another two well-known isotopes, i.e., ${ }^{220} \mathrm{Rn}$ (Thoron) and ${ }^{219} \mathrm{Rn}$. Among all these isotopes, ${ }^{222} \mathrm{Rn}$ is more stable (half-life 3.82 days) [Baskaran, 2016]. Therefore, monitoring of ${ }^{222} \mathrm{Rn}$ exhalation from the Earth's crust and its presence in the environment may helpful in the advancement of the various branches of science and technology such as precursors for Earthquake, oil and gas exploration, geothermal power exploration, atmospheric studies, the geochemical and geophysical study of marine systems, geochemical explorations of groundwater systems and many more [Baskaran, 2016].

In the present paper, we focus our attention on the measurement of the concentration of ${ }^{222} \mathrm{Rn}$ expelled out the hot spring in India. The area under consideration is Bakreswar hot spring (Agni Kunda) located (2352'50.0" N; $87^{\circ} 22^{\prime} 41.9^{\prime \prime} \mathrm{E}$ ) in the eastern part of India in the state of West Bengal. A cluster of hot springs is found in Bakreswar geothermal area and the region also shows intermediate geothermal activity [Ghose et al., 2002]. The paper includes the experimental procedures of continuous monitoring of the concentration of ${ }^{222} \mathrm{Rn}$ in hot spring gases. The ${ }^{222} \mathrm{Rn}$ emanation process seems to be influenced by multiple physical factors such as meteorological parameters, soil conditions, tectonic activities, tidal effects etc. The uneven influences of these factors with varying measures of randomness make the system nonlinear, which necessitates the use of nonlinear techniques [Mukherjee, 2012; Shumway and Stoffer, 2011]. Here, attention has been given on the nonlinear study of the ${ }^{222} \mathrm{Rn}$ gas emanation process. The main focus of this paper is to analyse the ${ }^{222} \mathrm{Rn}$ time series data recorded at Bakreswar area using the Fast Fourier Transform (FFT) technique. To verify the results of the analysis, a similar analysis also has been performed on a truncated and surrogate data set derived from the original time series. Further, the spectral indices and Hurst exponents were estimated by means of the linear regression of the distribution of log (power) vs. log (frequency) plots following the power law scaling relationship and suitable conclusions have been drawn on the dynamics of ${ }^{222} \mathrm{Rn}$ emanations based on the estimated values of spectral indices and Hurst exponents.

\section{Methodology}

\subsection{Experimental Methodology}

A field laboratory at Bakreswar hot spring area was established for continuous monitoring of concentrations of ${ }^{222} \mathrm{Rn}$ in hot spring. The radioactive gas ${ }^{222} \mathrm{Rn}$ was initially trapped in a giant inverted stainless-steel funnel kept under the hot spring (Agni Kunda) water in a region where the gas flux was considerably high. It was then allowed to pass through a moisture trap filter to eliminate the additional water vapour in the gas stream. The dry gas was then channelized to the Alpha GUARD Professional Radon Monitor PQ2000 PRO to measure the concentration of ${ }^{222} \mathrm{Rn}$ in the gas stream. Continuous monitoring of meteorological parameters and spring water temperature, along with its $\mathrm{pH}$ (in a discrete way), were also made. Schematic diagram of the experimental set up along with the details of the experimental procedures have been described elsewhere [Chaudhuri et al., 2018].

\subsection{Analytical Methodology}

In this paper, analysis has been made on the recorded time series data using various nonlinear techniques and statistical measures. The main purpose of the time series analysis is (i) to understand the physical process involved in the ${ }^{222} \mathrm{Rn}$ emission from the hot spring (ii) to identify patterns and trends of the radioactive gas emission from the hot spring vents and (iii) its relation with other natural phenomena such as tectonic activity, geothermal activity and health hazards due to radioactivity if any. Linear and nonlinear statistical measures such as mean, standard deviation, spectral index, Hurst exponent have been estimated using various analytical software, i.e., MATLAB R2016a, Origin Pro 8.5, and MS-Excel. With a motivation to understand the dynamics of the data set, we have considered the ${ }^{222} \mathrm{Rn}$ concentration recorded during the period August 2005 to December 2010. Recorded data have been segregated season-wise to recognise the seasonal variations for different seasons, such as summer (April-May 
of each year for 2006-2010), monsoon (June-July of each year for 2006-2010) and winter (December-January of each year for 2005-2010). A synthesized data has been prepared for each season, as mentioned above from the continuous original data set, taking into consideration of the data recorded in different seasons for every year. Here we have applied the well-known smoothing technique, i.e., Moving Average (MA) approach. To implement the Moving Average technique, each data point is replaced by the unweighted mean of the next $\mathrm{n}$ data points.

$$
x(i)_{M A}=\frac{x(i)+x(i+1)+\ldots+x(i+n)}{n}=\frac{1}{n} \sum_{k=i}^{i+n} x(k)
$$

Here we have selected $\mathrm{n}=24$ since the data was recorded on an hourly basis and the average is taken over the length of a day. The moving average time series data prepared for a particular season may contain various large fluctuations (i.e., $2 \sigma$, where $\sigma$ is the standard deviation of the data set). These large fluctuations may be originating out of the time to time influences of different geophysical, geochemical, meteorological, geotechnical, and seismic parameters on the data set [Wen et al., 2014]. The truncated data set of each seasonal segment was also prepared to understand the dynamics of the data series without the above-mentioned external influences. The truncation of the data from the original data set was made using developed Matlab code by means of successive elimination of the data point which were beyond the range of $\mathrm{M}-2 \sigma$ to $\mathrm{M}+2 \sigma$ (where M denotes the Mean and $\sigma$ denotes the standard deviation of the distribution in each cycle) until all the data point beyond the said range were eliminated. As a result, we get a new data set that contains less number of observations than the original but gets rid of the anomalies ${ }^{1}$. To analyze the nonlinearity prevalent in the data set, we have also synthesized surrogate data sets from the original one. Further, a comparison has been made among the moving average, surrogate, and truncated data sets. Surrogate data sets are phase-randomized data sets that mimic the autocorrelations of each of the variables and crosscorrelation between all variables and must also maintain the mean and standard deviation the same as the original data set [Prichard and Theiler, 1994]. There are different types of methods to generate surrogate data sets like IAAFT (Iterative Amplitude Adjusted Fourier Transform), AAFT (Amplitude Adjusted Fourier Transform), Annealing method etc. [Prichard and Theiler, 1994]. In this paper, the phase randomization method has been used where the data set is Fourier transformed to separate the phase and magnitude of the data. The data set is then randomized on the basis of the respective phases and finally, an Inverse Fourier Transform is used to convert the data back to its original form. Analysis of the time series data provides a correlation of fluctuations of the parameters under consideration with those occurring at a previous point of time [Shumway and Stoffer, 2011], and thus its analysis provides an interesting insight into the behavior of the system. The correlational components embedded in the time series are explored by converting them to the frequency domain [Bloomfield, 2004] since each correlational factor persists its characteristic frequency. Hence in this paper, the focus was also given to frequency domain analysis techniques such as Fast Fourier Transform (FFT) and power spectral density (PSD). The recorded ${ }^{222} \mathrm{Rn}$ time series data has been analyzed by FFT to understand the dynamics of the recorded data in the frequency domain as it may provide additional hidden information. Here, we have applied the technique which was proposed by Cooley and Tukey [Cooley and Tukey, 1965]. The method facilitates to reduce drastically the computation time, which is normally required in the conventional Discrete Fourier transform (DFT). If $x=\left(x_{0}, x_{1}, \ldots, x_{N-1}\right) \in C^{N}$ then DFT of $\mathrm{x}$ is defined as [Wörner, 2008]:

$$
X(k)=\frac{1}{n} \sum_{k=i}^{i+n} x(k) \exp \left(\frac{-2 j k \Pi}{N}\right),
$$

where, $\mathrm{k}=0,1,2 \ldots \mathrm{N}-1$ and $\mathrm{X}(\mathrm{k})=\left(\mathrm{X}_{0}, \mathrm{X}_{1}, \ldots \mathrm{X}_{\mathrm{N}-1}\right)$.

\footnotetext{
${ }^{1}$ A fluctuation is considered as an anomaly when the data points of the original data series lie out of the range of $\mathrm{M}-2 \sigma$ to $\mathrm{M}+2 \sigma$ (where $\mathrm{M}$ is the mean and $\sigma$ is the standard deviation of the truncated data set originated from the original data set) and if it has lasted for at least a considerable amount of time [Chaudhuri et al., 2011; Hartman and Levy, 2005; Virk, 1993; Thomas, 1988; Wakita et al., 1985].
} 


\section{Chiranjit Maji et al.}

Moreover, it helps us to identify the contribution of different frequencies in the magnitudes, i.e., concentrations of ${ }^{222} \mathrm{Rn}$ for our case. In addition to that, the paper deals with the distribution of power in different frequencies, i.e., PSD plots, which were estimated using Parseval's theorem [Hayes, 1998]. The motivation behind the analysis of ${ }^{222} \mathrm{Rn}$ time series data using the PSD is to represent the data in the frequency domain in a new sequence X(f), which reflects the contribution of each frequency component in the time series data. The PSD plots provided a lot of information about the processes that follow the inverse power law scaling behavior (1/f process) [Eke et al., 2002], which is expressed as:

$$
S(f)=\frac{1}{f^{\beta}}
$$

Generally, 1/f processes are classified into two categories, i.e., (i) Fractional Gaussian noise (fGn) and (ii) Fractional Brownian motion ( $\mathrm{fBm}$ ). $\mathrm{fGn}$ is a form of probability distribution where a part of the signal remains independent of the part taken for the position of the signal. On the contrary, fBm deals with another form of probability distribution where the distribution in a larger segment is equal to distribution in a smaller segment when the distribution in the larger segment is rescaled. The Hurst exponent is used to establish whether the data is in the form of pure white noise (totally random) or there exists some sort of correlation among the causes and effects. Moreover, it may provide information about the dynamics of ${ }^{222} \mathrm{Rn}$ emanations, i.e., the process is either $\mathrm{fGn}$ or $\mathrm{fBm}$. The relation between Hurst exponent $(\mathrm{H})$ and the power spectrum $\left(\frac{1}{f^{\beta}}\right)$ are expressed in the following way [Schaefer et al., 2014]:

$$
\begin{aligned}
& H_{f G n}=(\beta+1) / 2,-1 \leq \beta \leq 1 \\
& H_{f B m}=(\beta-1) / 2,-1 \leq \beta \leq 3
\end{aligned}
$$

Thus depending on the estimated value of $\mathrm{H}$ using the above-said equations, the process is designated as either fGn or fBm.

\section{Results and Discussions}

The experimental data recorded at Bakreswar hot spring site has been analyzed using different time series analysis techniques such as Moving Average technique, truncated data analysis method, and surrogate data procedure to properly understand the dynamics of the data set. Moreover, the FFT technique has been applied to obtain the power spectral density plots and to estimate the Hurst exponents. Moving average ${ }^{222} \mathrm{Rn}$ time series recorded for more than

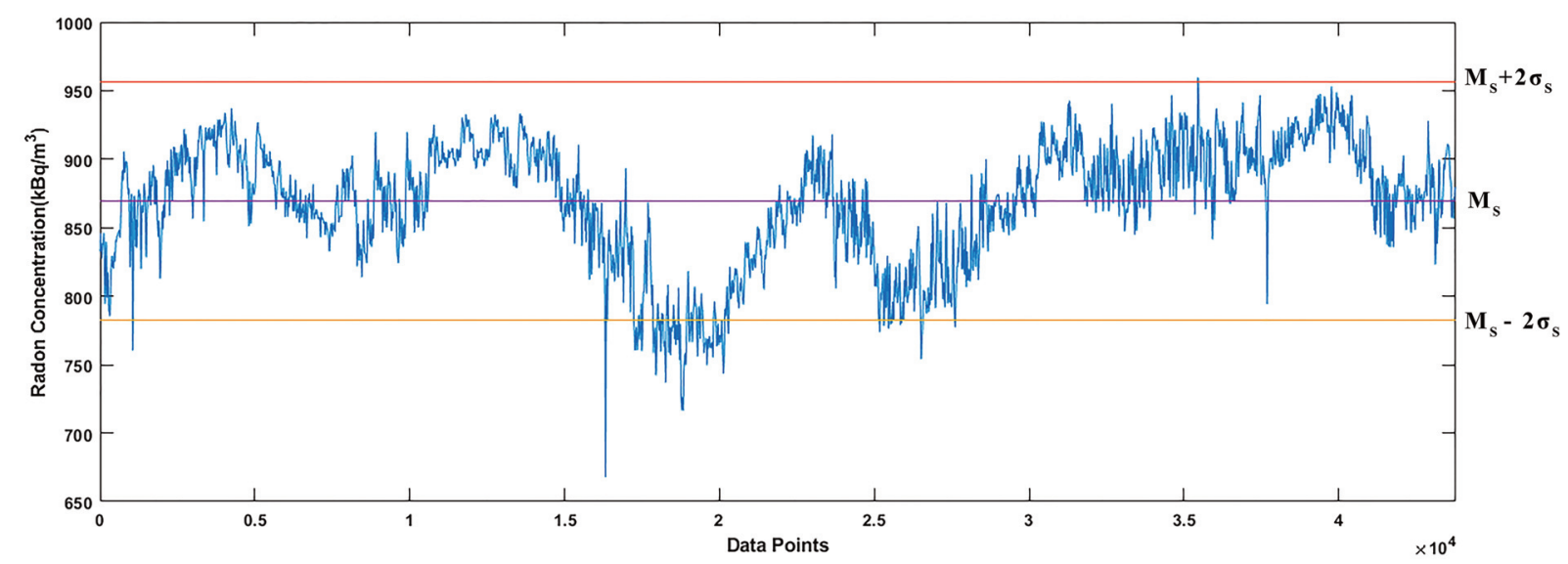

Figure 1. Temporal variation in concentration of ${ }^{222} \mathrm{Rn}$ emitted from Bakreswar hot spring recorded during August 2005December 2010 
consecutive 5 years (1st August 2005- 31st December 2010) is plotted and shown in Figure 1. Here, variation in concentration of ${ }^{222} \mathrm{Rn}$ contains maximum value $960 \mathrm{kBq} / \mathrm{m}^{3}$ and minimum value $668 \mathrm{kBq} / \mathrm{m}^{3}$ with an average value

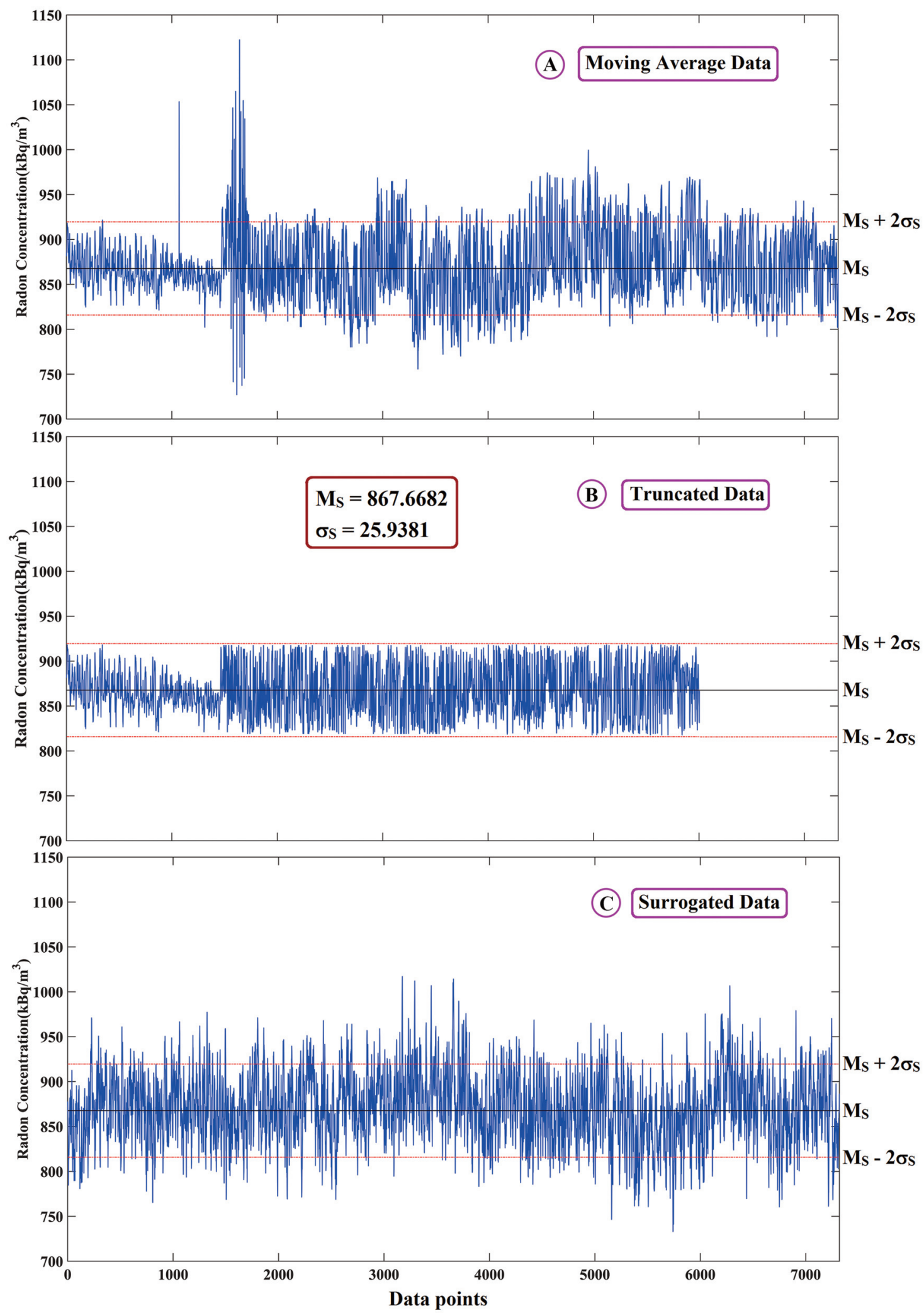

Figure 2. Fluctuation in ${ }^{222} \mathrm{Rn}$ emission during the summer time: (window A: Moving Average data set; window B: Truncated data set; window C: Surrogate data set). 


\begin{tabular}{|c|c|c|c|c|}
\hline S1. No. & Parameters & Summer (A) & Monsoon (B) & Winter (C) \\
\hline \multicolumn{5}{|c|}{ (a) Length $(\mathrm{L})$ of the time series data $\left(\mathrm{kBq} / \mathrm{m}^{3}\right)$} \\
\hline 1 & Moving Average & 7320 & 7320 & 7440 \\
\hline 2 & Truncated & 6004 & 6571 & 5107 \\
\hline 3 & Surrogate & 7319 & 7319 & 7439 \\
\hline \multicolumn{5}{|c|}{ (b) Maximum value $\left(\mathrm{kBq} / \mathrm{m}^{3}\right)$} \\
\hline 1 & Moving Average & 1122 & 1106 & 1004 \\
\hline 2 & Truncated & 918 & 942 & 944 \\
\hline 3 & Surrogate & 1017 & 1050 & 1026 \\
\hline \multicolumn{5}{|c|}{ (c) Minimum value $\left(\mathrm{kBq} / \mathrm{m}^{3}\right)$} \\
\hline 1 & Moving Average & 727 & 520 & 511 \\
\hline 2 & Truncated & 818 & 774 & 871 \\
\hline 3 & Surrogate & 733 & 689 & 775 \\
\hline \multicolumn{5}{|c|}{ (d) Mean (M) } \\
\hline 4 & Moving Average & 871 & 853 & 890 \\
\hline 5 & Truncated & 868 & 854 & 910 \\
\hline 6 & Surrogate & 871 & 853 & 893 \\
\hline \multicolumn{5}{|c|}{ (e) Standard deviation $(\sigma)$} \\
\hline 7 & Moving Average & 38.12 & 51.71 & 40.92 \\
\hline 8 & Truncated & 25.93 & 41.63 & 17.06 \\
\hline 9 & Surrogate & 38.12 & 51.71 & 40.92 \\
\hline
\end{tabular}

Table 1. Comparison of statistical parameters across seasons for all the three data sets.

of $869 \mathrm{kBq} / \mathrm{m}^{3}$ and standard deviation 43.44 . In this paper, we have also analyzed the observed temporal variations (moving average type), truncated data, and surrogate data sets that were prepared from the original time series data, as mentioned earlier for different seasons such as summer, monsoon and winter. Temporal variations (moving average type) in the concentration of ${ }^{222} \mathrm{Rn}$ only for the summer season are shown in Figure 2 (window A). Here ${ }^{222} \mathrm{Rn}$ concentration seems to vary within maximum value $1122 \mathrm{kBq} / \mathrm{m}^{3}$ and minimum value $727 \mathrm{kBq} / \mathrm{m}^{3}$ with an average value of $871 \mathrm{kBq} / \mathrm{m}^{3}$ and standard deviation 38.12. Figure 2 (window B) reflects the same for the truncated data set prepared for the summer season. The concentration of ${ }^{222} \mathrm{Rn}$ appears to fluctuate within maximum value $918 \mathrm{kBq} / \mathrm{m}^{3}$ and minimum value $818 \mathrm{kBq} / \mathrm{m}^{3}$ with an average value of $868 \mathrm{kBq} / \mathrm{m}^{3}$ and standard deviation 25.93 . According to the analysis of the surrogate data (Figure 2, window C), ${ }^{222} \mathrm{Rn}$ varies within maximum value $1017 \mathrm{kBq} / \mathrm{m}^{3}$ and minimum value $733 \mathrm{kBq} / \mathrm{m}^{3}$ with an average value $871 \mathrm{kBq} / \mathrm{m}^{3}$ and standard deviation 38.12 . Moreover, a comparison has been performed among the moving average, truncated, and surrogate data relating to the summer season. Details of the statistical features are shown in Table 1 (column A).

In a similar fashion, temporal variation (moving average type) in the concentration of ${ }^{222} \mathrm{Rn}$ only for the monsoon season is shown in Figure 3 (window A). In this case concentration of ${ }^{222} \mathrm{Rn}$ shows a variation within the range of maximum value $1106 \mathrm{kBq} / \mathrm{m}^{3}$ and minimum value $520 \mathrm{kBq} / \mathrm{m}^{3}$ with an average value of $853 \mathrm{kBq} / \mathrm{m}^{3}$ and standard deviation 51.71. Moreover, the truncated data set prepared for the monsoon seems to fluctuate within maximum value $942 \mathrm{kBq} / \mathrm{m}^{3}$ and minimum value $774 \mathrm{kBq} / \mathrm{m}^{3}$ with an average value of $854 \mathrm{kBq} / \mathrm{m}^{3}$ and standard deviation 41.63 as shown in Figure 3 (window B). On the other hand, the surrogate data (Figure 3, window C) prepared for the monsoon season shows a variation in ${ }^{222} \mathrm{Rn}$ concentration within maximum value $1050 \mathrm{kBq} / \mathrm{m}^{3}$ and minimum value $689 \mathrm{kBq} / \mathrm{m}^{3}$ with an average value $853 \mathrm{kBq} / \mathrm{m}^{3}$ and standard deviation 51.71 . Details of the statistical features for the moving average, truncated and surrogate data relating to the monsoon are also shown in Table 1 (column B).

On the other contrary, Figure 4 (window A) depicts the temporal variations (moving average type) in the concentration of ${ }^{222} \mathrm{Rn}$ for the winter. During the winter season, the concentration of ${ }^{222} \mathrm{Rn}$ has a fluctuation within range of maximum value $1004 \mathrm{kBq} / \mathrm{m}^{3}$ and minimum value $511 \mathrm{kBq} / \mathrm{m}^{3}$ with an average value of $890 \mathrm{kBq} / \mathrm{m}^{3}$ and standard deviation 40.92. Figure 4 (window B) shows the truncated data set for the winter. Here the concentration of ${ }^{222} \mathrm{Rn}$ is observed to fluctuate within $944 \mathrm{kBq} / \mathrm{m}^{3}$ (maximum value) and $871 \mathrm{kBq} / \mathrm{m}^{3}$ (minimum value) having an 
average value of $910 \mathrm{kBq} / \mathrm{m}^{3}$ and standard deviation 17.06. In the case of the surrogate data for the winter, as shown in Figure 4 (window C), ${ }^{222} \mathrm{Rn}$ concentration varies within maximum value $1026 \mathrm{kBq} / \mathrm{m}^{3}$ and minimum value 775 $\mathrm{kBq} / \mathrm{m}^{3}$ with an average value $893 \mathrm{kBq} / \mathrm{m}^{3}$ and standard deviation 40.92. Table 1 (Column c) reflects the details of the statistical features for the moving average, truncated, and surrogate data for the winter period.

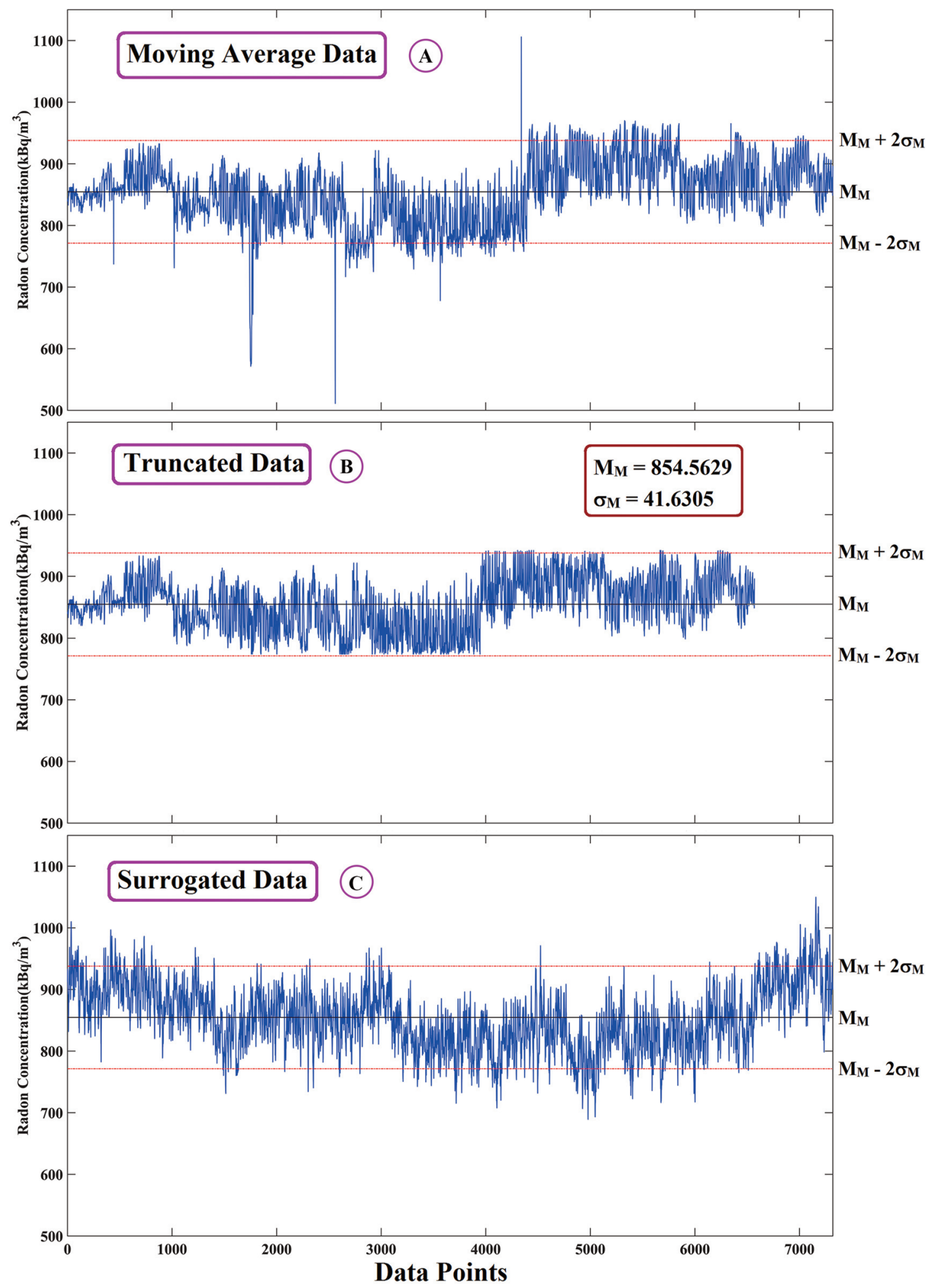

Figure 3. Fluctuation in ${ }^{222} \mathrm{Rn}$ emission during the monsoon time: (window A: Moving Average data set; window B: Truncated data set; window C: Surrogate data set). 


\begin{tabular}{|c|c|c|c|c|}
\hline S1. No. & Parameters & Summer (A) & Monsoon (B) & Winter (C) \\
\hline \multicolumn{5}{|c|}{ (a) Spectral index( $\beta$ ) } \\
\hline 1 & Moving Average & 2.35 & 2.22 & 2.02 \\
\hline 2 & Truncated & 2.45 & 2.41 & 2.18 \\
\hline 3 & Surrogate & 2.39 & 2.24 & 2.01 \\
\hline \multicolumn{5}{|c|}{ (b) Hurst exponent(H) } \\
\hline 4 & Moving Average & 0.67 & 0.61 & 0.51 \\
\hline 5 & Truncated & 0.72 & 0.70 & 0.59 \\
\hline 6 & Surrogate & 0.69 & 0.62 & 0.50 \\
\hline
\end{tabular}

Table 2. Comparison of spectral index and Hurst exponent across the seasons for all the three data sets.

It was observed from Table 1 that for the summer, the mean is $0.34 \%$ less in the truncated model and comparable in the surrogate model with respect to that of the moving average set. The standard deviation is $31.98 \%$ less in the truncated model and comparable in the surrogate model with respect to that of the moving average set. On the other hand, in the case of the monsoon, the mean is $0.12 \%$ more in the truncated model and comparable in the surrogate model with respect to that of the moving average set. The standard deviation is $19.49 \%$ less in the truncated model and comparable in the surrogate model with respect to that of the moving average set. In the winter season scenario is a little bit different. For the winter, the mean is $2.25 \%$ more in the truncated model and comparable in the surrogate model with respect to that of the moving average set. The standard deviation is $58.31 \%$ less in the truncated model and comparable in the surrogate model with respect to that of the moving average set. The statistical parameters also show considerable variation across seasons. The mean for the moving average data set decreases $2.07 \%$ in the monsoon season and increases $2.18 \%$ in the winter as compared to that of the summer season. The standard deviation increases by $35.65 \%$ and $7.35 \%$ in the monsoon and the winter, respectively, with respect to that of the summer. The mean for the truncated data set decreases $1.61 \%$ in the monsoon season and increases $4.84 \%$ in the winter as compared to that of the summer season. The standard deviation increases by $60.43 \%$ in the monsoon season and decreases $34.21 \%$ in the winter season with respect to that of the summer season. The mean for the surrogate data set decreases $2.07 \%$ in the monsoon season and increases $2.23 \%$ in the winter as compared to that of the summer season. The standard deviation increases by $35.65 \%$ in the monsoon season and increases by $7.35 \%$ in the winter season with respect to that of the summer season. From the above results, it is observed that mean and standard deviation for any particular season, corresponding to the moving average data and the surrogate data, have not changed significantly, and it is consistent with the definition of the surrogate data. It is notable that the mean of the truncated data is less with respect to the moving average data for the summer season. This refers to the presence of more positive anomalies with higher amplitude in the moving average data set during this period. On the other hand, for the months of the monsoon and winter, the mean of the truncated dataset is higher when compared to that of the moving average dataset. This accordingly confers to the presence of a higher number of negative anomalies with lower amplitude in the said periods. These conclusions are very much consistent with Figures 2, 3, and 4 (windows A for each). Moreover, the stability of the system under consideration for any particular season may be quantified by the percentage of reduction of standard deviation. Less reduction of the standard deviation of the truncated data with respect to that of the moving average data for any season indicates that the data set is highly fluctuating in nature, and the system is more unstable in that interval. Here, said reduction in the monsoon is very less, which confers the said geothermal system is more unstable due to the external influences such as frequent rainfall and varying groundwater levels etc. Using the same reasoning, it is well understood that the system is highly stable in the winter and moderately stable during the summer. This can be attributed due to meteorological factors like sporadic rainfall due to north-western during the summer season. The absence of most kinds of meteorological instability (like rainfall) during the winter months makes the system highly stable.

In this paper, we have applied the FFT technique on the recorded time series data to find out the correlation of fluctuations of concentration of ${ }^{222} \mathrm{Rn}$ at a particular time with those occurring at a previous point of time. This helps in exploring interesting features about the dynamics of the ${ }^{222} \mathrm{Rn}$ emission. Moreover, the distribution of power in 
different frequencies has been explored by means of PSD plots. This may throw some light on the power spectral behavior of the ${ }^{222} \mathrm{Rn}$ emission, i.e., either Fractional Gaussian noise (fGn) or Fractional Brownian motion (fBm). Figure 5 depicts the power spectral plot for the moving average data for three different seasons (window $\mathrm{A}$ for the summer; window $\mathrm{B}$ for the monsoon and window $\mathrm{C}$ for the winter).

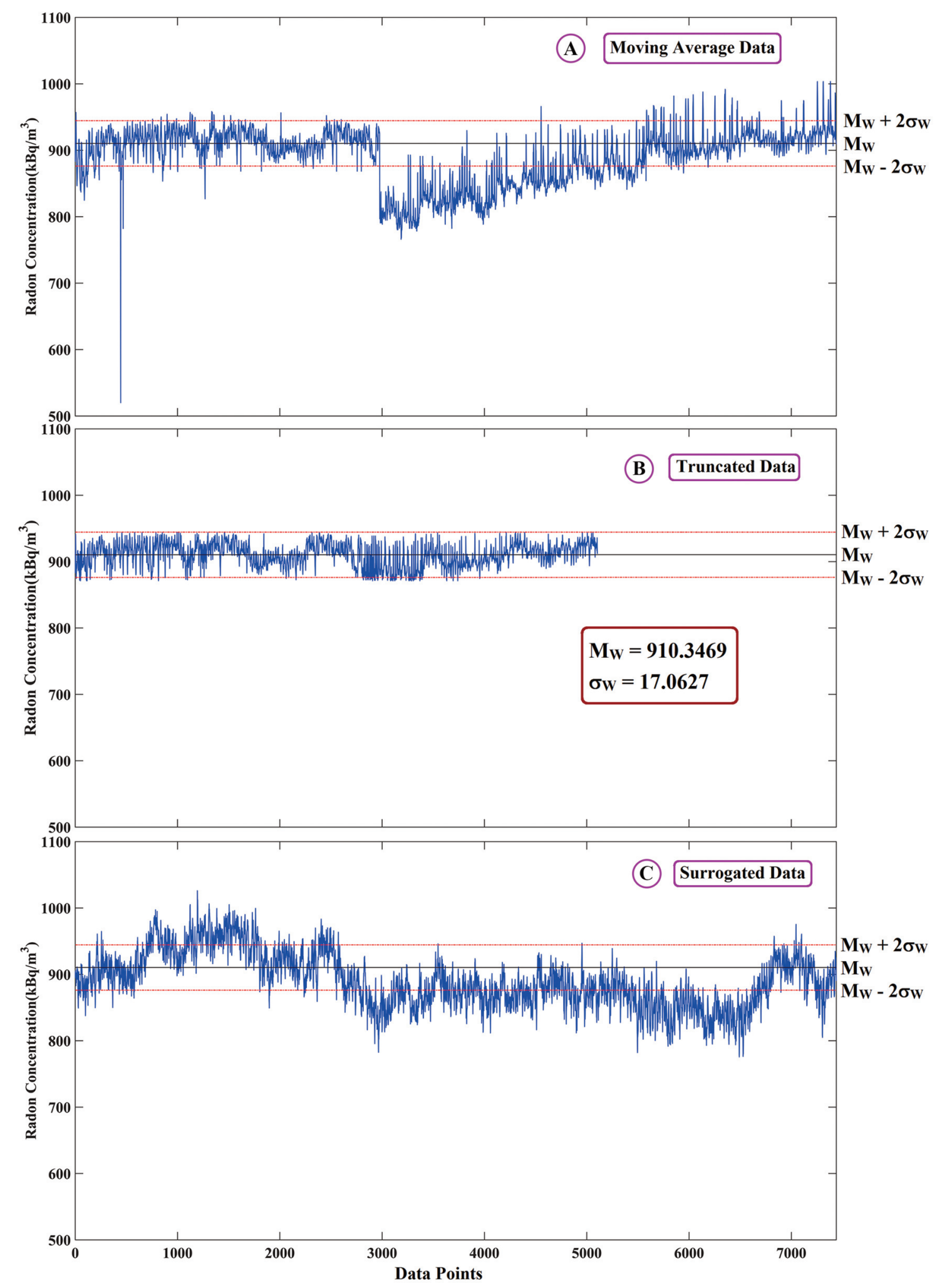

Figure 4. Fluctuation in ${ }^{222} \mathrm{Rn}$ emission during the winter time: (window A: Moving Average data set; window B: Truncated data set; window C: Surrogate data set). 


\section{Chiranjit Maji et al.}

There could be the influence of the Earth's tides on the ${ }^{222} \mathrm{Rn}$ gas expelled from the Bakreswar hot spring [Weinlich et al., 2006]. The displacement of solid Earth surfaces under the influence of the gravitational force of the sun, and the moon is known as Earth tide. It principally bears a strong resemblance to ocean tides. Earth tides have a periodic influence occurring on a semi-diurnal, diurnal, fortnightly, and semi-annual basis. The diurnal constituent of the Earth tide P1 (time period $24.066 \mathrm{hr}$.) occurs at $0.997 \mathrm{cpd}$ (cycles per day) (as shown in Figure5). The solar diurnal constituent S1 (time period 24 hr.) occurs at $1 \mathrm{cpd}$ (also shown in Figure5). It is observed clearly that the peaks occurring at the abscissa of 1 cpd vary significantly in different seasons. Since Earth tides are the diurnal phenomenon associated with the influence of gravitational fields on the Earth, it does not exhibit a seasonal variation. Hence the windows A, B, and C indicate the presence of other factors that may vary with season and inhibit the effect of Earth tides on the gas emanations (concentration, flow rate etc.) [Hartmann and Wenzel, 1995]. During the summer season, the temperature of the air remains relatively high. This implies lesser moisture content in air as well as in soil and a more porous state of the soil. This allows greater freedom for movement of the gas molecules, i.e., ${ }^{22} \mathrm{Rn}$. Hence any external influence like that of Earth tides on the emanation of gas would be more prominent. On the other hand, during the monsoon seasons, the soil contains augmented amounts of moisture. This would cause the soil particles to coalesce together, thus restricting the movement of the gas underneath. This would further reduce the effective influence of the Earth tides on the gas molecules' movement. In the case of the winter seasons, the soil particles are tightly packed due to the presence of moderate moisture and relatively low temperatures. This situation may severely restrict the movement of the gas underneath. In such a scenario, the effect of factors like Earth tides would be significantly reduced. This explains the relative change of peaks corresponding to $1 \mathrm{cpd}$ abscissa. The observation is also consistent with Figure 6 (window A for the summer; window B for the monsoon and window C for the winter), where the same arguments can be put forward for the surrogate data set. The data points in the original (moving average) signal corresponding to $1 \mathrm{cpd}$ abscissa may be exceeded the $(\mathrm{M}-2 \sigma)$ and $(\mathrm{M}+2 \sigma)$ range. Hence these data points are eliminated by the truncation algorithm. This is evident in Figure 7 (window A: summer and window C: winter), which does not show a relatively high peak at the expected abscissa of $1 \mathrm{cpd}$. From Table I, it is observed that the standard deviation $(\sigma)$ values for the moving average data are less for the summer and the winter as compared to that of the monsoon. This implies that the span of variation used in the truncation algorithm is also less in the summer and the winter as compared to the monsoon. Hence, several anomalies would get truncated in the summer and the winter, resulting in lesser no of data points corresponding to $1 \mathrm{cpd}$ abscissa (Figure 7, window A and window $\mathrm{C}$ ). The peak at $1 \mathrm{cpd}$ abscissa is still prominent in the monsoon (Figure 7, window B) as a result of less truncation due to the higher value of $\sigma$. The relatively high value of $\sigma$ implies lesser stability in the reservoir system during the monsoon season. This can be attributed to greater variations of meteorological parameters like rainfall, humidity, temperature etc.

Figures 8, 9 and 10 depict the $\log$ power vs. $\log$ frequency (log p vs. $\log$ f) plots for the three data sets: moving average, truncated and surrogate data sets respectively and season wise they are labeled as window A (summer), window B (monsoon) and window $C$ (winter). We estimated the spectral index $(\beta)$ and Hurst exponent $(H)$ for each case from the slope of the log p vs. log f plots by means of the linear regression. In the present paper, the emphasis was also given on the estimation of the Hurst exponents of the recorded ${ }^{222} \mathrm{Rn}$ time series data. Details of the estimated spectral index and Hurst exponent are given in Table 2.

Here, the Hurst exponents of the truncated data are higher than that of the moving average data for all the seasons. The fact implies that due to the truncation of the anomalies from the moving average data, the series exhibit more stronger trend [Qian and Rasheed, 2004], i.e., the anomalous external influences interrupt the system to attain more trend. The Hurst exponents of the surrogate data for all the seasons are very much similar to that of the moving average data, and this is in accordance with its definition. The value of Hurst exponent of the moving average data for the monsoon is lower than that of the summer due to the presence of a higher number of anomalies in the monsoon season, i.e., more trend is present in the moving average data for the summer compared to that for the monsoon season. Moreover, Hurst exponent of the moving average data for the winter season is very near to 0.5 , implying that the system is very likely to exhibit random walk like behavior. However, the values of spectral indices for all the three models across all seasons seem to be greater than 1 . This indicates that the dynamics of the ${ }^{222} \mathrm{Rn}$ gas emanation from hot springs exhibits Fractional Brownian motion. Further, the Hurst exponents for the moving average, truncated, and surrogate model across all three seasons appear to be greater than 0.5, which implies that the Fractional Brownian motion is persistent. 
Nonlinear Radon discharge at Bakreswar
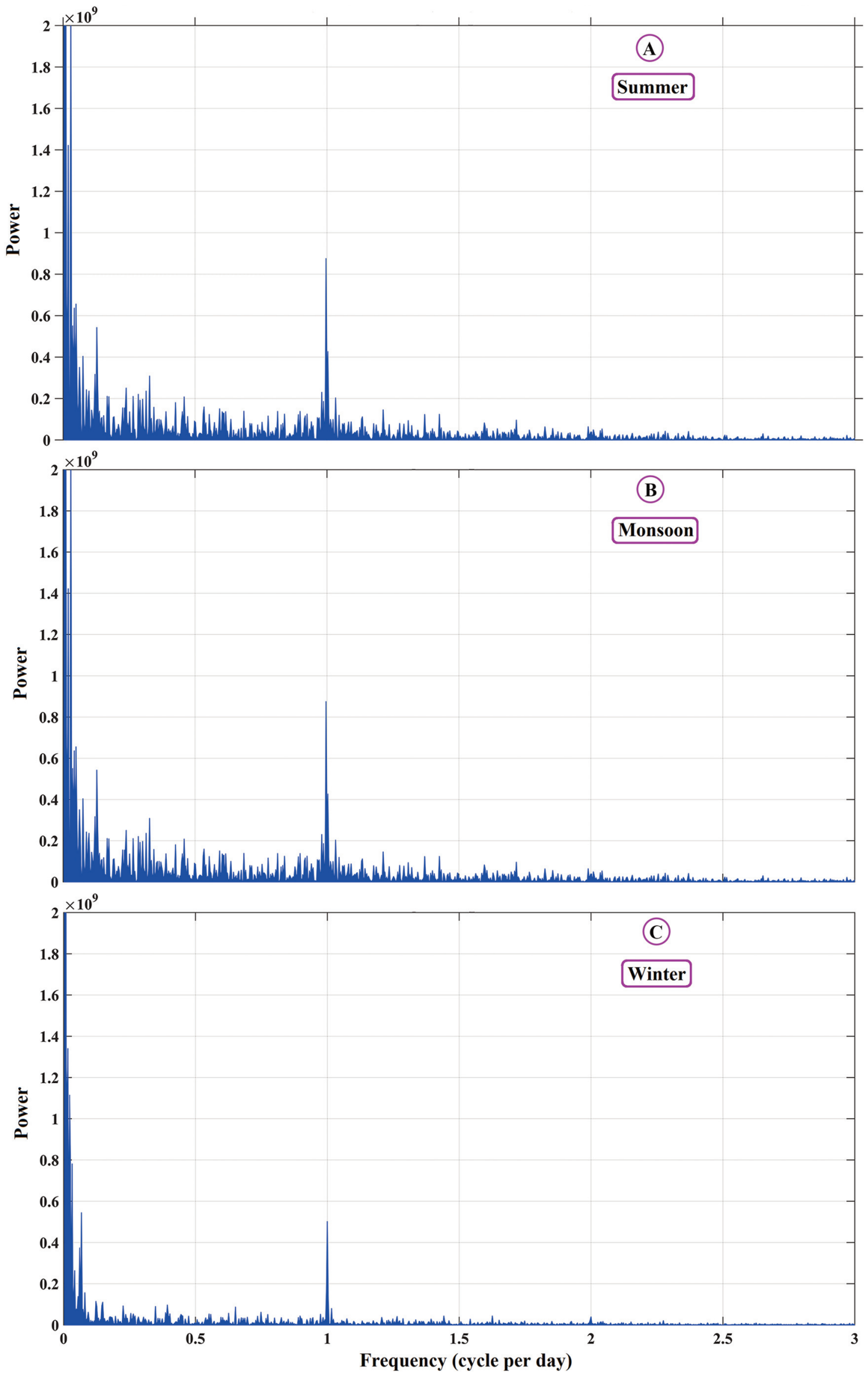

Figure 5. Power spectral density plot for moving average data set of ${ }^{222} \mathrm{Rn}$ for three different seasons: (window A: summer; window B: monsoon; window C: winter). 
Chiranjit Maji et al.
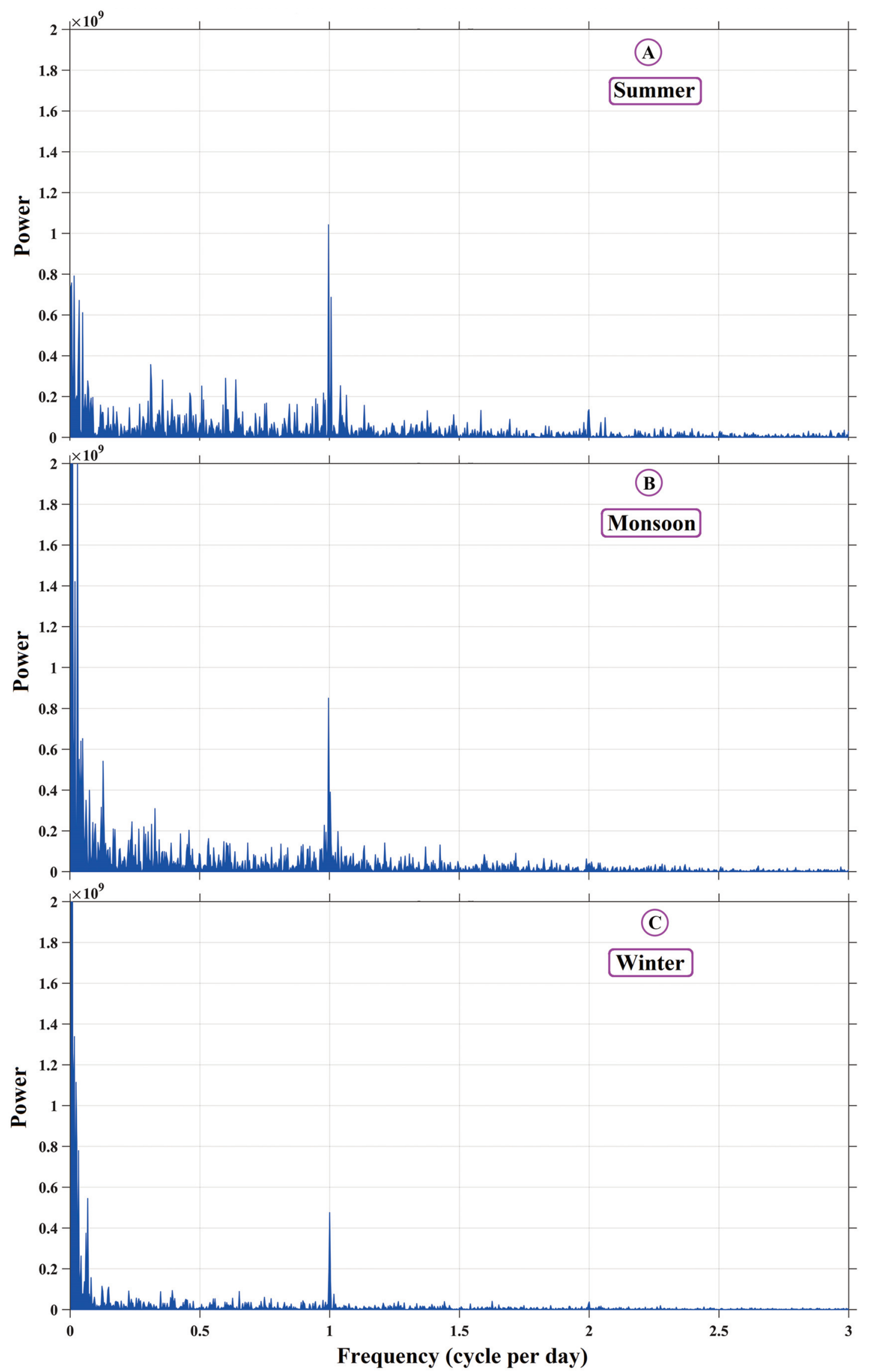

Figure 6. Power spectral density plot for the surrogate data set of ${ }^{222} \mathrm{Rn}$ for three different seasons: (window A: summer; window B: monsoon; window C: winter). 

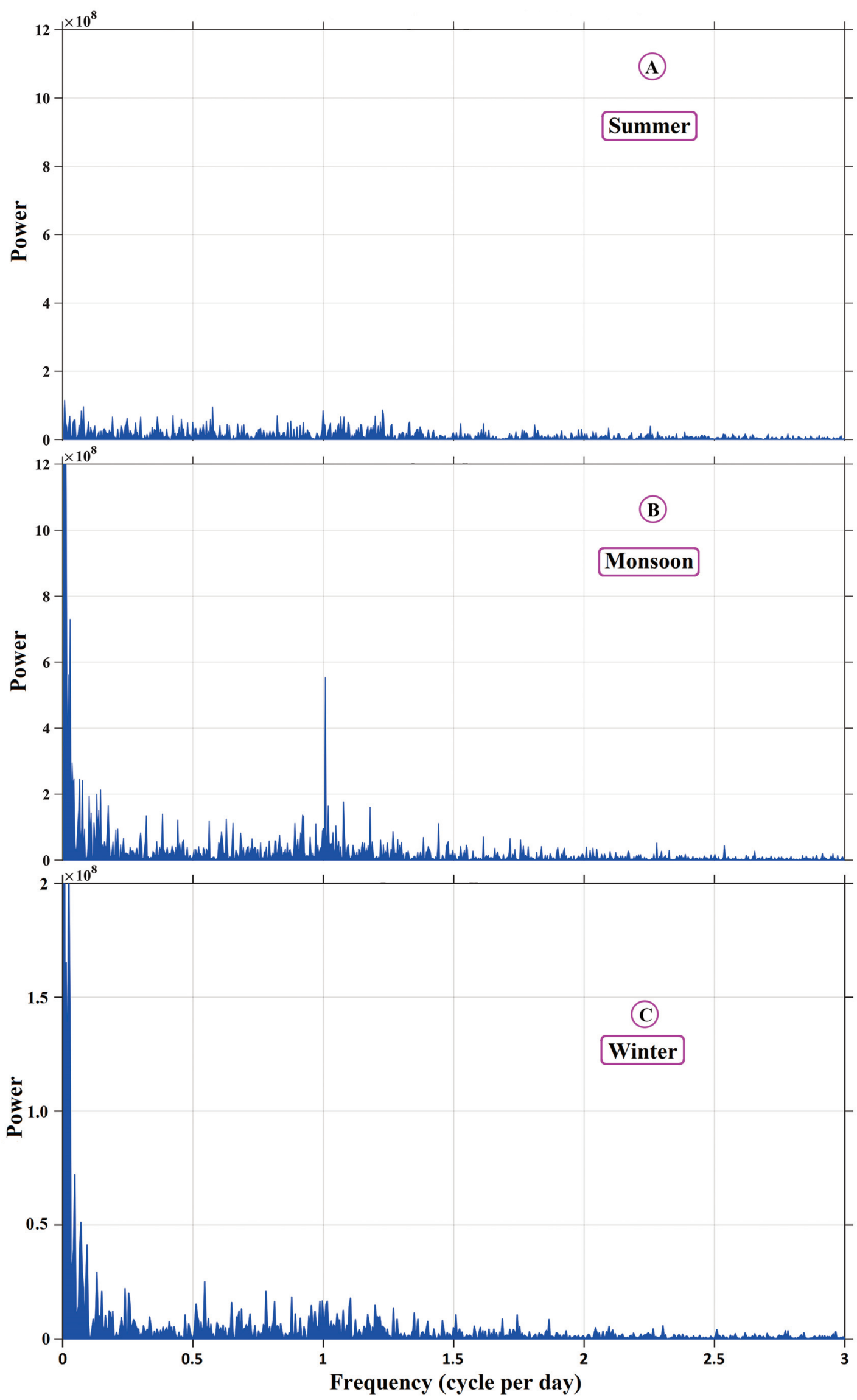

Figure 7. Power spectral density plot for the truncated data set of ${ }^{222} \mathrm{Rn}$ for three different seasons: (window A: summer; window B: monsoon; window C: winter). 
Chiranjit Maji et al.
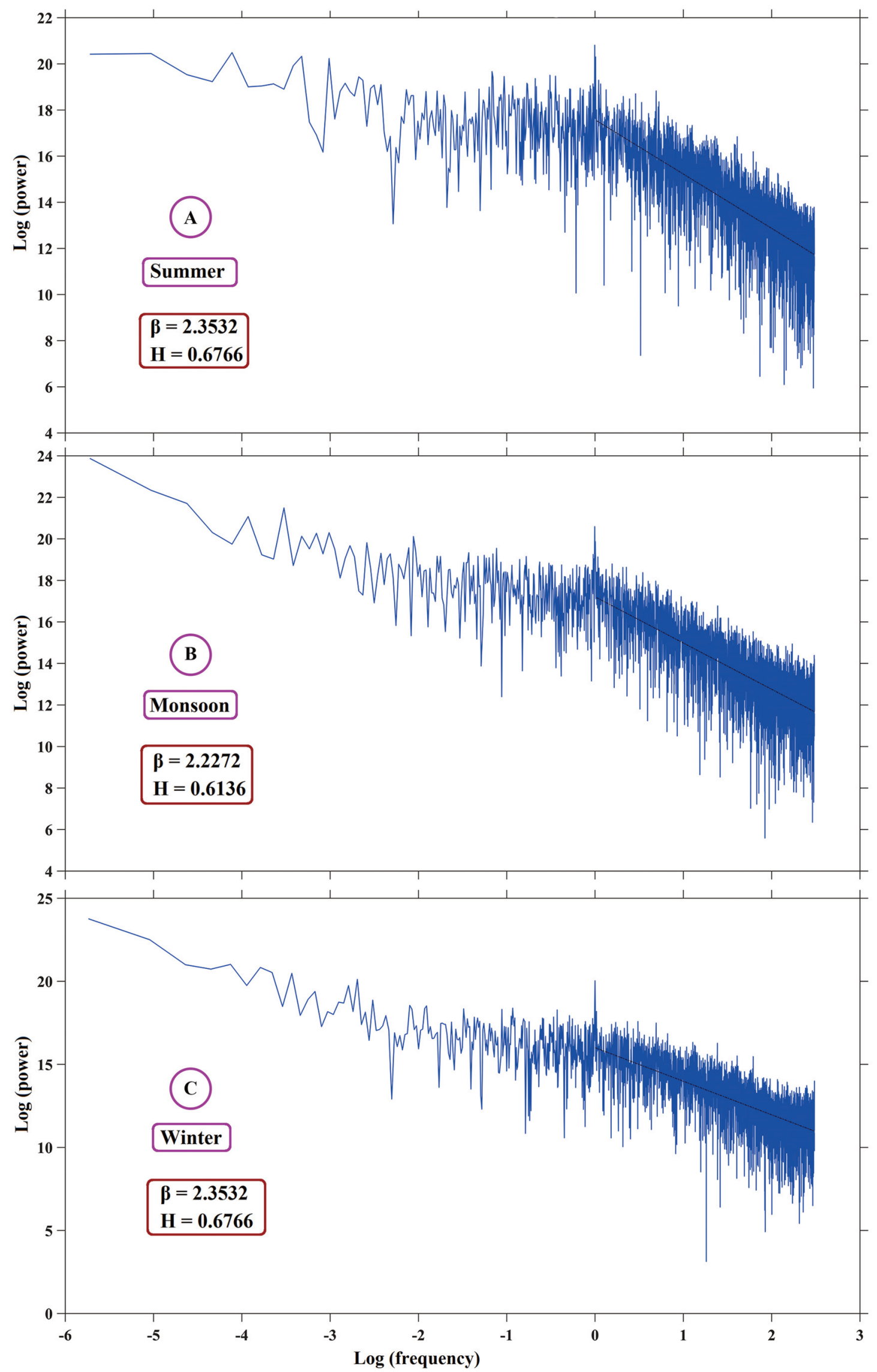

Figure 8. Log p vs. $\log \mathrm{f}$ distribution plot for the moving average data set of ${ }^{222} \mathrm{Rn}$ for three different seasons: (window A: summer; window B: monsoon; window C: winter). 
Nonlinear Radon discharge at Bakreswar

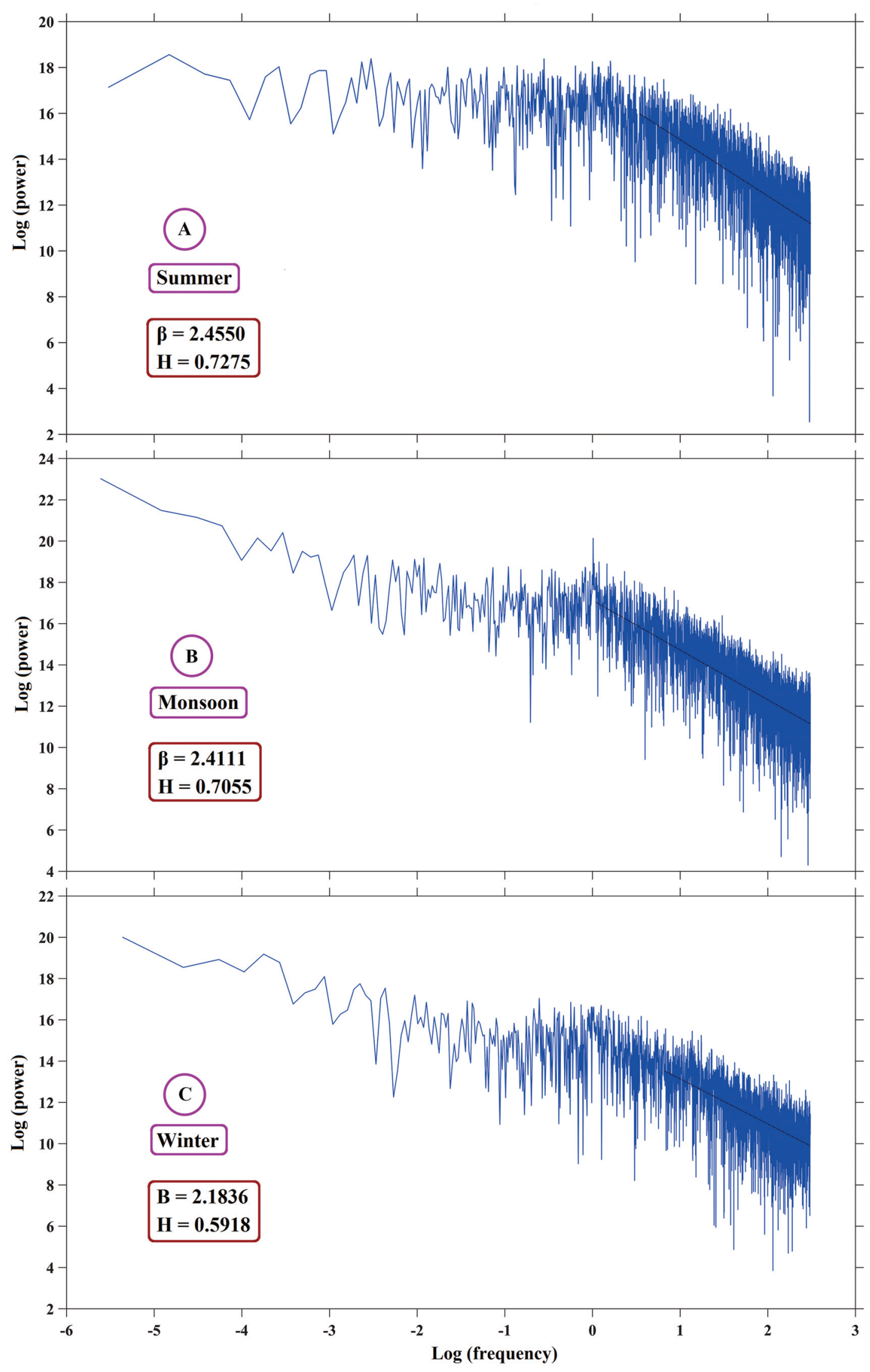

Figure 9. Log $\mathrm{p}$ vs. $\log \mathrm{f}$ distribution plot for the truncated data set of ${ }^{222} \mathrm{Rn}$ for three different seasons: (window A: summer; window B: monsoon; window C: winter). 
Chiranjit Maji et al.

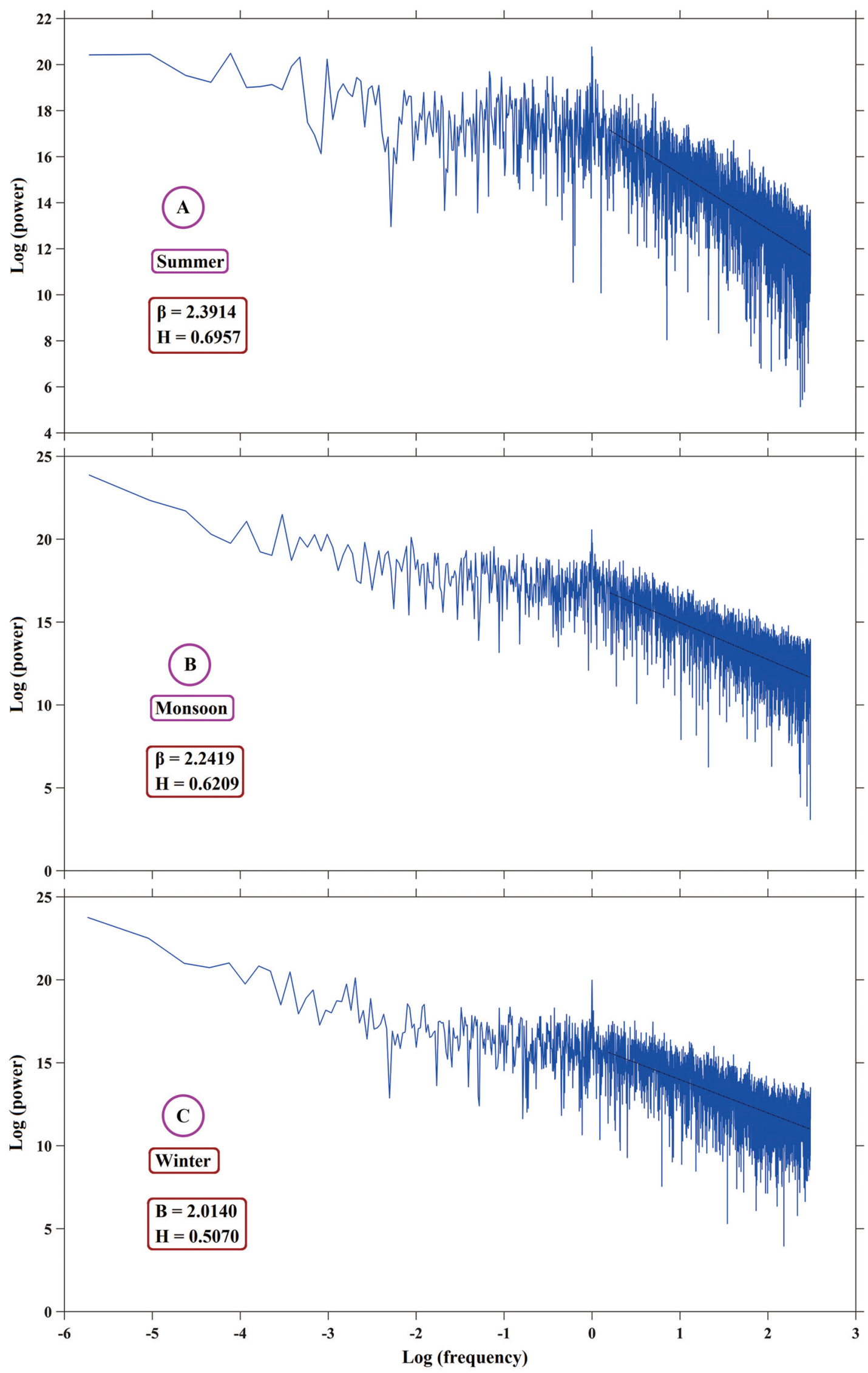

Figure 10. Log p vs. $\log \mathrm{f}$ distribution plot for the surrogate data set of ${ }^{222} \mathrm{Rn}$ for three different seasons: (window A: summer; window B: monsoon; window C: winter). 


\section{Conclusion}

Thus, the analysis of the ${ }^{222} \mathrm{Rn}$ data set reveals that the distribution of concentration of ${ }^{222} \mathrm{Rn}$ over time falls in the category of persistent Fractional Brownian motion. Statistical parameters like mean and standard deviation show distinct variations across seasons. The standard deviations remain consistent across all the three models except in the truncated data set. It can be concluded that the concentration of the ${ }^{222} \mathrm{Rn}$ gets affected by geophysical, geochemical, and meteorological disturbances. The system is highly unstable in the monsoon season, quite stable in the winter season, and moderately stable during the summer. The influence of the Earth tides on the concentration of ${ }^{222} \mathrm{Rn}$ is prominent from characteristic peaks on the PSD plots. The presence of seasonal factors is also noted by their inhibitive effect on the Earth's tide maxima.

Acknowledgment. The authors owe a debt of gratitude to the National Institute of Technology Durgapur (NIT Durgapur) and the Ministry of Human Resource Development (MHRD), Govt. of India, for providing the financial and other Institutional support for carrying out the research activities. One of the authors, ANSI, would like to acknowledge DSTSERB for the support in carrying out this work.

\section{References}

Baskaran, M. (2016). Radon: A tracer for geological, geophysical and geochemical studies, Springer, 9-13. Bloomfield, P. (2004). Fourier analysis of time series: an introduction, John Wiley \& Sons, 234-236.

Chaudhuri, H., N.K. Das, R.K. Bhandari, P. Sen, B. Sinha (2010). Radon activity measurements around Bakreswar thermal springs, Radiat. Meas. 45(1), 143-146.

Chaudhuri, H., C. Maji, K. Seal, S. Pal, M.K. Mandal (2018). Exploration of geothermal activity using time series analysis of subsurface gases data from Bakreswar hot springs area, eastern India, Arabian J. Geosci. 11(12), 1-17.

Chaudhuri, H., W. Bari, N. Iqbal, R. K. Bhandari, D. Ghose, P. Sen and B. Sinha (2011). Long range gas-geochemical anomalies of a remote earthquake recorded simultaneously at distant monitoring stations in India, Geochem. J. 45, 137-156.

Cooley, J.W. and J.W. Tukey (1965). An algorithm for the machine calculation of complex Fourier series, Math. Comput. 19(90), 297-301.

Eke, A., P. Herman, L. Kocsis, L. Kozak (2002). Fractal characterization of complexity in temporal physiological signals, Physiol. Meas. 23(1), R1.

Ghose, D., D. Chowdhury, B. Sinha (2002). Large-scale helium escape from Earth surface around Bakreswar-Tantloi geothermal area in Birbhum district, West Bengal and Dumka district, Jharkhand, India, Curr. Sci. 82, 993-996.

Hartmann, T. and H.G. Wenzel (1995). The hw95 tidal potential catalogue, Geophys. Res. Lett. 22(24), 3553-3556.

Hartmann, J. and J. Levy (2005). Hydrogeological and Gasgeochemical earthquake precursors-a review for application, Nat. Hazard 34, 279-304.

Hayes, M.. (1998). Schaum's outline of digital signal processing, McGraw-Hill, Inc., 64.

İçhedef, M., M. M. Saç, C. Harmanşah, C. Taskopru (2014). Two year evolution of radon emission and tectonic movements in Tuzla Fault, Seferihisar-Izmir. Applied Radiation and Isotopes, 86, 102-108.

dx.doi.org/10.1016/j.apradiso.2013.12.011.

Neri, M., E. Ferrera, S. Giammanco, G. Currenti, R. Cirrincione, G. Patane, V. Zanon (2016). Soil radon measurements as a potential tracer of tectonic and volcanic activity, Sci. Rep. 6, 1-12. DOI: 10.1038/srep24581.

Mukherjee, K. (2012). A review of robust estimation under conditional heteroscedasticity. In: Rao, T. S., Rao, S. S., Rao, C. R. (eds) Time series analysis: methods and applications, 1st edn. Elsevier Science \& Technology, NorthHolland, pp 123-154.

Pereira, E.B. (1980). Some Problems Concerning the Migration and Distribution of Helium-4 and Radon-222 in the Upper Sediments of the Crust- A Theoretical Model and the Development of a Quadrupole Ion Filter for Measuring Helium at the Soil-Air Interface. PhD Thesis, Rice University.

Prichard, D. and J. Theiler (1994). Generating surrogate data for time series with several simultaneously measured variables, Phys. Rev. Lett. 73(7), 951-954. 


\section{Chiranjit Maji et al.}

Qian, B., K. Rasheed (2004). Hurst Exponent and financial market predictability, IASTED conference on "Financial Engineering and Applications"(FEA 2004), 203-209.

Schaefer, A., J. S. Brach, S. Perera and E. Sejdi'c (2014). A comparative analysis of spectral exponent estimation techniques for $1 / \mathrm{f}^{\beta}$ processes with applications to the analysis of stride interval time series, J. Neurosci. Methods 222, 118-130.

Shumway, R.H. and D.S. Stoffer (2011). Time series analysis and its applications with R examples, Springer, New York, 47-82.

Tarakçı, M., C. Harmanşah, M.M. Sa, M. İçhedef (2014). Investigation of the relationships between seismic activities and radon level in Western Turkey, Appl. Radiat. Isot. 83, 12-17. http://dx.doi.org/10.1016/j.apradiso.2013.10.008

Thomas, D. (1988). Geochemical precursors to seismic activity, Pure Appl. Geophys. 126, 241-266.

Virk, H. (1993). Radon and Earthquake prediction in India: present status, Int. J. Radiat. Appl. Instrum. 22, 483-494.

Wakita, H., Y. Nakamura, Y. Sano (1985). Groundwater radon variations reflecting changes in regional stress fields,. Earthq. Predict. Res. 3, 545-557.

Weinlich, F. H., E. Faber, A. Boušková, J. Horálek, M. Teschner and J. Poggenburg (2006). Seismically induced variations in Mariánské Lázně fault gas composition in the NW Bohemian swarm quake region, Czech Republic- A continuous gas monitoring, 421, 89-110.

Wen, T., J. Du, T. Ji, X. Wang, B. Deng (2014). Use of ${ }^{222} \mathrm{Rn}$ to trace submarine groundwater discharge in a tidal period along the coast of Xiangshan, Zhejiang, China, J. Radioanal. Nucl. Chem. 299, 53-60.

Wörner, S. (2008). Fast Fourier Transform. Swiss Federal Institute of Technology Zurich, Zurich, 2. Available at http://pages.di.unipi.it/gemignani/woerner.pdf, accessed on March 29, 2019.

Zmazek, B., M. Zivcic, L. Todorovski, S. Dzeroski, J. Vaupotic, I. Kobal (2005). Radon in soil gas: How to identify anomalies caused by earthquakes, J. Appl. Geochem. 20, 1106-1119. doi:10.1016/j.apgeochem.2005.01.014

*CORRESPONDING AUTHOR: Chiranjit MAJI,

Department of Physics,

National Institute of Technology Durgapur,

Mahatma Gandhi Avenue,

Durgapur-713209, West Bengal, India

e- mail: cm.15ph1102@phd.nitdgp.ac.in

chiranjit.nitdphysics@yahoo.in

(c) 2020 the Istituto Nazionale di Geofisica e Vulcanologia.

All rights reserved 